\title{
Aportes del diálogo interreligioso a la paz en Colombia ${ }^{2}$
}

\author{
Contributions of interreligious dialogue \\ for peace in Colombia
}

\section{Resumen}

La pluralidad religiosa del continente latinoamericano y caribeño, que también es evidente en Colombia, revela la necesidad del diálogo interconfesional e interreligioso. No obstante, dicho diálogo tendría un mayor provecho si se hiciera sobre la ortopraxia más que sobre la ortodoxia. En nuestro contexto, el diálogo interreligioso está llamado a preguntarse por los aportes que puede hacer a la construcción de la paz en este momento histórico. Si la religión tiene un papel por jugar en los años venideros, este debe ser el de "re-ligar" a hombres y mujeres - incluso no creyentes - para que puedan reconocerse y convivir en su diferencia. Una de las claves de acción está en el cuidado del otro: del prójimo, de la comunidad a la cual pertenece y de la naturaleza o la casa común, como bien la ha llamado el Papa Francisco en su última encíclica, Laudato Si. Ahora bien, lo que queda por establecer son los múltiples modos, ojalá colaborativos, para que esto acontezca en nuestra sociedad.

Palabras clave: diálogo interreligioso, pluralidad religiosa, cuidado del otro, civilidad, paz.

\begin{abstract}
Religious plurality of Latin American and Caribbean continent, Colombia included, reveals the need for an interfaith and interreligious dialogue. However, such a dialogue would be more profitable if it were done on a more orthopraxis way than on an orthodox one. In our context, interreligious dialogue is questioned about the contributions it can offer to peace building in this Colombian historical moment. If religion has a role to play in the years to come, it must be relinked to men and women, even non-believers, so that they can recognize and live together amongst their differences. One key action is to take care of each other: the neighbor, the community to which he/she belongs, and nature, or the 'common house', as Pope Francis has called it in his last encyclical 'Laudato Si'. Now, what remains to be established are the multiple modes, hopefully collaborative ones, so this could really happen within our society.
\end{abstract}

Keywords: interreligious dialogue, religious plurality, caring for the other, civility and peace.

\section{Recibido: 9 de octubre de 2015, evaluado: 2 de noviembre de 2015, aprobado: 5 de noviembre de 2015}

1 Doctor en Teología. Profesor asociado de la Facultad de Teología de la Universidad Javeriana. Miembro del Grupo de Investigación Didaskalia.

2 Articulo de reflexión derivado de las investigaciones realizadas en el Grupo de Investigación Didaskalia, acerca del papel del diálogo interreligioso en la construcción de la paz en Colombia, en el tiempo actual. 


\section{Introducción}

Mientras escribía este artículo me sorprendió gratamente la noticia sobre el acuerdo de justicia entre el Gobierno colombiano y las Farc, pero igualmente me desconcertó la actitud de unos cuantos que han protestado, no solo por lo establecido en él, sino por la forma como se llegó al mismo. ¿Acaso nos hemos acostumbrado a la violencia de tal manera que somos incapaces de dialogar y preferimos las vías de hecho, beligerantes, vindicativas y guerreristas? ¿Será que poco a poco hemos constituido un habitus que no nos permite reconocer al otro y creemos que dialogar es procurar a toda costa nuestra propia razón, juicio y voluntad? Sin duda, todo esto nos lleva a pensar en lo que somos y en la historia que ha marcado a nuestro país en los últimos sesenta años.

No obstante, para enfocarme en el tema de este escrito, debo decir que el punto en el cual nos encontramos dentro del proceso de paz es un gran paso; insisto, es "un" paso al cual se le deben sumar otros tantos, muchos más, los de aquellos que creemos que otra Colombia es posible y, por tanto, tenemos una cuota de responsabilidad para que la paz se haga presente en cada lugar: en nuestras familias, en nuestros trabajos, en nuestros barrios o veredas y en los grupos u organizaciones de los cuales formamos parte. Para ello es necesario cambiar el "chip" en cada uno de nosotros, de tal modo que esta paz no sea un "amor de verano" sino que, en este momento de fragilidad, tenga toda nuestra atención, como la de una madre con su recién nacido.

Pues bien, como "lo religioso" está presente en nosotros, la pregunta directa es ¿cuál es el aporte que podemos hacer (mejor todavía, como considero que es un imperativo, "que debemos hacer") como hombres y mujeres "de religión", aunque no sea la misma, en la construcción de la paz en nuestro país? Esta pregunta, así formulada, nos implica. Pero podemos abstraerla en estos términos: ¿cuáles son los aportes del diálogo interreligioso a la paz en Colombia?
Para intentar responder lo anterior, me detendré en primer término en dos presupuestos que no podemos olvidar: el primero, el nuevo mapa religioso colombiano y latinoamericano nos muestra que somos un pueblo diverso y, de manera especial, en el ámbito religioso; y el segundo, el diálogo interreligioso resulta necesario e ineludible si queremos construir conjuntamente, desde la pluralidad que nos caracteriza, nuestro proyecto de nación. $Y$ en segundo término repararé en la pregunta y, por tanto, expondré las contribuciones que puede hacer el diálogo interreligioso a la paz.

\section{Una aproximación al mapa religio- so de Colombia y Latinoamérica}

Antes del concilio ecuménico, el cardenal Motta enunció estas palabras, las cuales evidencian una actitud ante la pluralidad religiosa que tal vez no es la más afortunada:

Además del fetichismo de nuestros indígenas y del de aquellos pueblos provenientes de Asia y de Europa, nuestro pueblo recibió esta triste herencia oriunda también de África, a través de los antiguos esclavos negros. Hoy en día, por una insensata aberración y falta de espíritu, se cultiva incluso la macumba africana como un folclórico pretexto snob. Y se da culto a tan bárbara superstición de magia negra precisamente en centros que deberían ser más representativos de la civilización brasileña, como Río de Janeiro y Bahía. La práctica de tales abusos entre cristianos es una ignominia... La macumba es uno de los mayores atentados contra la fe, contra la moral, contra nuestros derechos educativos, contra la higiene y contra la seguridad. Es un atestado alarmante de nuestra ignorancia religiosa y científica y de la insuficiente protección que la policía nos ofrece. (Ligorio, 2001)

Desde tiempo atrás, la cartografía religiosa ha señalado que América Latina y el Caribe contienen la mayor población católica del mundo. Tal realidad hunde sus raíces en el proceso histórico vivido: la presencia de la iglesia católica durante cinco siglos tuvo gran impacto en la configuración de los órdenes cultural, social, político, económico, educativo y artístico. Sin embargo, 
también es cierto que la segunda mitad del siglo $\mathrm{XX}$ vio nacer un panorama diferente aunque algunos ojos no lo quisieran ver y siguieran creyendo que este era un continente eminentemente católico. Más aún, las voces que clamaban por un diálogo interreligioso fueron desatendidas ya que parecía improcedente gastar energías en dialogar con religiones inexistentes en estas coordenadas espaciotemporales. De hecho, las representaciones judías, musulmanas, hinduistas, sintoístas y budistas, entre otras, fueron simplemente negadas al tratarse de minorías.

Adicionalmente, en la alborada del siglo XXI pronto nos dimos cuenta de que el catolicismo del pueblo latinoamericano y caribeño había dejado de ser monocromático; dentro de él comenzó a habitar tal diversidad de matices que algunos grupos sufren resistencias para ser aceptados dentro de la misma iglesia católica. Además, qué decir de tantos otros que han abandonado las filas católicas para engrosar aquellas otras de las iglesias cristianas que hasta hace poco eran señaladas como sectas, así como de aquellos que se hicieron miembros de otras religiones diferentes a la cristiana. Esta migración, junto con otros fenómenos, ha hecho que el escenario cultural y religioso se haya complejizado.

Al lado de las diversas iglesias cristianas con carta de ciudadanía en nuestro continente (anglicana, luterana, calvinista, adventista, bautista y menonita, entre otras) también han venido a formar parte de nuestra realidad religiosa nuevos movimientos religiosos procedentes en su mayoría de Estados Unidos, como el neopentecostalismo y la new age. Al mismo tiempo, hemos visto la entrada en escena de formas religiosas autóctonas que existían un tanto ocultas como el candomblé, la umbanda y el batuque brasileños, el rastafari jamaiquino, la santería y el espiritismo cubanos, el shangó trinitense y los cultos africanos de Colombia y Venezuela, por nombrar solo algunas de las más conocidas (Ramírez, 2008). En todas ellas coexisten elementos propios del cristianismo - de forma particular, del catolicismo- y de las religiones autóctonas aborígenes.
Al respecto, François Houtart (2001) distingue tres direcciones en las cuales ha tenido lugar el movimiento de conversión prevaleciente en América Latina en nuestros días: el auge del pentecostalismo; el rescate de la identidad indocristiana y afrocristiana; y lo que ha sido codificado por los estudiosos bajo el nombre genérico de nuevos movimientos religiosos, movimientos no todos cristianos y que, en muchos casos, muestran incluso la transculturación de expresiones religiosas orientales.

De manera particular, en Colombia también hemos visto un cambio en el mapa religioso que, por un lado, ha visibilizado algunas religiones que, aunque minoritarias, han estado presentes desde el siglo pasado, al menos; y, por otro lado, ha permitido el nacimiento o llegada y fortalecimiento de otros movimientos religiosos. Al respecto, me remito a los trabajos Globalización $y$ diversidad religiosa en Colombia (Bidegain y Demera, 2005) y De microempresas religiosas a multinacionales de la fe. La diversificación del cristianismo en Bogotá (Beltrán, 2006). En términos generales, los autores de estas obras concluyen lo siguiente:

- Ha habido un aumento significativo de la comunidad protestante en Colombia: pasó de 9.000 personas en 1930 a 69.000 en 1969, 4 millones en 1990 y 8 en 2014.

- Las religiones amerindias han permitido la afirmación de la identidad nacional y sus rituales son practicados por diversos sectores sociales mestizos. Es frecuente la presencia de autoridades indígenas en foros y actividades académicas en universidades y otras instituciones interesadas en conocer y comprender su cosmovisión.

- Los rituales de origen africano presentan una gran expansión, tanto en los departamentos con presencia de poblaciones de origen africano como en las grandes ciudades, donde diversos sectores sociales se acercan a participar de ritos y expresiones religiones diversas.

- Comunidades y ritos de origen oriental, como budistas e hinduistas, han logrado 
establecerse en núcleos urbanos, impactando a poblaciones de clase media.

- El fortalecimiento del Islam y su adhesión va en aumento, particularmente en aquellas poblaciones hijas de inmigrantes siriolibaneses instalados en Colombia desde la década de 1920 en las regiones costeras caribeña y pacífica.

Todo lo anterior, que merecería un mayor despliegue, nos permite constatar que hoy es innegable la pluralidad religiosa en América Latina, al igual que en Colombia. Por eso, cabe preguntarnos qué vamos a hacer: ¿seguiremos creyendo que la religión de la mayoría es la religión verdadera o arriesgaremos formas creativas y respetuosas de encuentro entre las diferentes iglesias, religiones y movimientos religiosos? ¿Llegaremos a un diálogo provechoso que nos permita alcanzar una vida buena y feliz? ¿Podemos ir más allá de discusiones baldías centradas en una "sana ortodoxia" a cometidos conjuntos que se mueven dentro de la ortopraxis, aunque sea imperfecta?

\section{El diálogo interreligioso como condición posibilitadora}

Cada ser humano tiene que conquistar lo humanum en una forma única y personal. Dentro de este propósito la religión juega un papel importante. La tarea de toda religión es dar una visión y posibilidad concretas de cómo el ser humano (individual o colectivamente) puede alcanzar lo bumanum. Para ello hay muchos caminos. La religión es un sendero hacia lo bumanum ya se llame salvación, liberación o de cualquier otra forma genérica (Panikkar, 2007, p. 27).

Los que conocemos la Iglesia Católica o pertenecemos a ella sabemos que el diálogo interreligioso es la asunción sincera de lo que ha pedido el Concilio Vaticano II $^{3}$ en diversos documentos como la Constitución dogmática sobre la Iglesia Lumen Gentium, la Constitución pastoral Gaudium et Spes, el Decreto sobre la actividad misionera de la Iglesia Ad Gentes, la Declaración sobre la libertad religiosa Dignitatis Humanae, y, de manera especial, la Declaración sobre la relación de la Iglesia con las religiones no cristianas Nostra Aetate, en donde encontramos ideas tan audaces como esta: "en nuestra época, en la que el género humano se une cada vez más estrechamente y aumentan los vínculos entre los diversos pueblos, la Iglesia considera con mayor atención en qué consiste su relación con respecto a las religiones no cristianas" (Pablo VI, Nostra Aetate). Como bien lo dice la misma declaración, ese encuentro enriquece aún más el cristianismo porque las otras religiones también han realizado un intento genuino por dar respuesta a los grandes enigmas de la condición humana ${ }^{4}$. Aunque muchos aceptamos esta verdad, también es cierto que otros no. Prueba de ello es la misma Nostra Aetate, la cual tuvo un camino tortuoso antes de su aprobación por parte de los padres conciliares, como bien lo refiere Pérez (2014, pp. 67-69).

Con todo, resulta de suma importancia para el cristianismo - y si se quiere, para la Iglesia católi$\mathrm{ca}-$ el reconocimiento salvífico de las religiones no cristianas que hace Nostra aetate, como lo señala Pérez:

Todas las religiones pueden salvar. Los cristianos somos compañeros de camino con todas las personas de buena voluntad que buscan el Misterio, abriéndose con confianza y humildad a Aquel/Aquella que les trasciende, con lo que la Iglesia hace causa común con toda la humanidad (Pérez, 2014, p. 69).

Con esta afirmación se reitera la interpretación del jesuita indio Michaël Amaladoss, quien dice "los fieles de otras religiones logran la

3 Un estudio detallado de los documentos conciliares en esta clave se encuentra en Dupuis (2000, pp. 233-250).

4 "Los hombres esperan de las diversas religiones la respuesta a los enigmas recónditos de la condición humana, que hoy como ayer, conmueven íntimamente su corazón: ¿qué es el hombre, cuál es el sentido y el fin de nuestra vida, el bien y el pecado, el origen y el fin del dolor, el camino para conseguir la verdadera felicidad, la muerte, el juicio, la sanción después de la muerte? ¿Cuál es, finalmente, aquel último e inefable misterio que envuelve nuestra existencia, del cual procedemos y hacia donde nos dirigimos?" (NA, 1). 
salvación no a pesar de ellas, sino en y mediante ellas. Son 'caminos de salvación', es decir, diversos modos de participar en la única salvación del Padre, por el Hijo y en el Espíritu Santo" (1988, p. 244). Si esto es así, descubrimos que el encuentro entre las religiones es urgente y necesario: según Panikkar (1999a), "ser es estar juntos". A este propósito, el teólogo indocatalán afirma:

Es tan vital que quizá el destino y la supervivencia de la raza humana dependa de este encuentro donde la simbiosis sea positiva y no haya un parasitismo mórbido ni mutua destrucción. Me atrevería a decir que, hoy en día todas las tradiciones de la humanidad no pueden resolver los interrogantes que el hombre hodierno se plantea. Incluso en el ámbito de la misma religión: nos estamos mordiendo la cola, vamos repitiendo las mismas cosas. El aggiornamiento solo ya no es suficiente en ninguna de las tradiciones religiosas de la humanidad. Se necesita algo más que ponerse al día. Es una prueba de vitalidad del hecho religioso y humano que ninguna tradición sea suficiente para dar respuesta a los interrogantes que hoy tiene planteados la existencia humana, porque muchos de sus problemas ya no han salido, precisamente, de una determinada área [cultural y] religiosa, sino del encuentro mismo; son nuevos como problemas, y nueva también debe ser la solución. (Panikkar, 1999b, p. 354)

Panikkar nos dice que "el diálogo es ante todo duo-logo, es decir, dos logoi que se encuentran y se manifiestan recíprocamente sus presupuestos. El diálogo presupone que ninguno de los dos interlocutores es autosuficiente, perfecto, completo" (Panikkar, 2007, p. 361). No obstante, en aras de que el diálogo logre su cometido, hemos de superar la tendencia dialéctica que nos avoca a un enfrentamiento racional con el otro para esgrimir los mejores argumentos y "con-vencerlo" (derrotarlo). Antes bien, hemos de procurar un diálogo dialogal: un legein (encuentro) de dos "dialogantes" que se escuchan recíprocamente para intentar comprender lo que están diciendo $y$, por qué no, intentar salidas a los problemas que les aquejan en su contexto particular (Panikkar, 2006, p. 31) .

Si lo anterior ocurre, el diálogo dialogal podría ayudar a superar aquellos temores que emergen ante tal encuentro y que podemos ilustrar con preguntas como las siguientes:

¿Por qué buscar la verdad religiosa entre los seres humanos (si la fuente de la verdad se halla en Dios y Él es quien se revela)? ¿No habrá un indicio de apostasía en el diálogo interreligioso? ¿No debería yo esforzarme primeramente en conocer mejor las riquezas de mi propia tradición antes de aventurarme por caminos desconocidos, tratando de comprender aquello que los demás han dicho o pensado? ¿No se dará el caso de que yo ya no crea en la experiencia o en la revelación, cristalizadas ambas dentro de mi tradición? ¿Qué derecho tengo a servirme un coctel religioso según mis particulares apetencias? Esto es, ¿el diálogo interreligioso no revela una tendencia al eclecticismo y al sincretismo que traiciona mi falta de fidelidad o mi superficialidad? (Panikkar, 2005, p. 246).

Diluir estos temores no resulta fácil. Sin embargo, si caemos en cuenta de que la finalidad de toda religión es la de salvar, liberar, dar plenitud o procurar la trascendencia al hombre, también nos damos cuenta de que el diálogo interreligioso, más que una amenaza, es una oportunidad. Panikkar afirma:

"Difícilmente alguien podrá entender a fondo su religión sin tener una idea de la existencia y legitimidad de otros universos religiosos. Si los problemas importantes tienen para nosotros una sola expresión, tenderemos a pensar que nuestras concepciones (aunque necesiten ser refinadas) definen

5 El mismo Panikkar dice en otro de sus escritos: "es innegable que el diálogo está a la orden del día. No hay ningún aspecto de la vida humana en el cual el ser humano contemporáneo pueda sentirse individualmente autosuficiente. En la búsqueda de sí mismo el ser humano tropieza con el otro sin poderlo evitar. El otro no es solamente mi interlocutor dialéctico que me dice algo de sí mismo y pone resistencia a mis ideas; el otro también me ofrece por así decir, un reflejo inesperado de mí mismo. El encuentro desencadena una doble reacción: cada uno suscita en el otro una nueva toma de conciencia de sí mismo y viceversa. Dicho de otro modo, además del diálogo dialéctico está el 'diálogo dialogal'”' (Panikkar, 2005, p. 243). 
la realidad con validez universal [...] De ahí que el estudio de más de una religión nos cure del prurito de querer absolutizar nuestra religión convirtiéndola en la religión” (Panikkar, 2005, p. 246).

Es entonces cuando el diálogo es intrarreligioso $^{6}$ y se convierte, además, en un acto religioso-espiritual, en una búsqueda de la verdad salvadora. El pluralismo religioso ha de ser visto en su noble intención yendo más allá de una tendencia esnobista que se "fascina" por lo extraño que pudiera parecerle el otro y asimila acríticamente formas de pensar, de sentir y de actuar. Nada más lejos del diálogo interreligioso que el "sincretismo religioso" porque ocurriría un monismo que conlleva a la muerte de las religiones.

\section{Aporte del diálogo interreligioso a la paz: cuidar del otro}

Los dos presupuestos anteriores me permiten establecer la idea central de este artículo, la cual "defenderé" en este último apartado: el mayor aporte que puede hacer el diálogo interreligioso a la paz en nuestro país es el cuidado (enseñar el cuidado de..., aprender el cuidado de..., promover el cuidado de..., defender no a "capa y espada", sino por la vía del diálogo, el cuidado de...). En otras palabras el cuidado de... debería ser el motivo y el propósito que nos impulse a encontrarnos y trabajar juntos.

Volvamos a la declaración Nostra Aetate, que dice así: "la Iglesia católica no rechaza nada de lo que en otras religiones hay de santo y verdadero. Considera con sincero respeto los [sus] modos de obrar y de vivir" (Pablo VI, Nostra Aetate). Encontramos aquí una pista valiosa e insoslayable para dar cuenta de la pregunta inicial y sostener la idea central. Con toda seguridad, la Iglesia católica no está pensando el "sincero respeto" como una actitud contemplativa o de mutuo miramiento, ni como una actividad elucubrativa para "charlar deliciosamente" sobre temas superfluos; antes bien, cree profundamente que es posible construir caminos conjuntos de obrar y de vivir y, en nuestro caso, "obrar la paz" (entiéndase: construir, promover, trabajar por...) y, por supuesto, "con-vivir en paz".

No obstante, ¿cuáles serían el sujeto, el código y el marco que inscribirían esas formas de obrar y de vivir, o si lo prefieren, esas formas de ortopraxia por y para la paz derivadas del diálogo interreligioso? A mi modo de ver, el sujeto es el ser humano, el código es la alteridad y el marco estaría dado por las relaciones que le permiten alcanzar su salvación y plenitud. Vamos por partes.

\section{Con respecto al ser humano}

La salvaguarda del ser humano constituye una exigencia mínima de todas las religiones; pero se hace veraz, especialmente, cuando estas últimas se vuelcan sobre los empobrecidos, excluidos, estigmatizados o marginados. En otras palabras, "el día que las religiones unan sus luchas por las grandes causas de la humanidad (igualdad, justicia, fraternidad, liberación de los pobres) se reconciliarán entre sí, aproximarán su fe y comunión con Dios y habrán sellado el gran bien de la paz" (Forcano, 2008).

\section{Con respecto a la alteridad}

La alteridad es un criterio (ético) presente en muchas de las religiones. Muestra de ello es lo que se puede leer en sus textos sagrados, tal como lo presenta Küng (1999, p. 113): "lo que tú mismo no quieres, no lo hagas a otros hombres" (confucionismo); "no hagas a otros lo que quieres que ellos te hagan a ti" (judaísmo); "todo cuanto quieran que les hagan los otros hombres, háganlo

6 Al respecto Alonso nos hace caer en cuenta de lo siguiente: "podríamos convenir que cuando vinculamos el concepto de diálogo (u otro que por el contrario aluda a su ausencia, como exclusión) al de religión, estamos obligados a diferenciar, al menos, tres extensiones, ya se trate de un contexto nacional o global: el diálogo que propiamente llamamos interreligioso, que tiene lugar entre una religión y las otras; el que podríamos llamar intrarreligioso, por tener lugar en el interior de una misma religión; y otro que llamaría extrarreligioso, que puede aludir a los vasos comunicantes entre la religión y el mundo arreligioso e irreligioso, y que incluye el diálogo con la ciencia, con la políitca e incluso con el ateísmo, en un plano extremo" (Alonso, 2008, p. 16). 
también ustedes con ellos" (cristianismo); "ninguno de ustedes será un creyente mientras no desee para su hermano lo que desea para sí mismo" (islamismo); "una situación que no es agradable o conveniente para mí, tampoco lo será para él; y una situación que no es agradable o conveniente para mí, ¿cómo se la voy a exigir a otro?” (budismo); "no debería uno comportarse con otros de un modo que es desagradable para uno mismo; esta es la esencia de la moral" (hinduismo).

\section{Con respecto a sus relaciones}

Si las relaciones básicas del ser humano están dadas por un tú, un nosotros y un él, de aquí se desprenden tres ámbitos de cuidado: el cuidado del otro, de los otros y de lo otro.

\section{El cuidado "del otro"}

La preocupación por el otro surge en el momento en que a uno le importa lo que le pasa a ese otro; empero, para que me importe lo que le pasa al otro debo verlo, y para ello tengo que amarlo. Como ya dijimos, la palabra clave para comprender este planteamiento es alteridad. Considero que el filósofo judío E. Lévinas es uno de los que más ha desarrollado este concepto, constituyéndolo en epicentro de su propuesta. Este principio no emerge del yo sino del otro o la otra cuya presencia nos ob-liga, nos solicita, nos afecta. Por eso, nuestro yo se define desde nuestra responsabilidad para con el otro (citado por Vila, 2004, p. 54). El autor nombrado afirma con convencimiento: "desde el momento en que el otro me mira yo soy responsable de él sin siquiera tener que tomar responsabilidades en relación con él; su responsabilidad me incumbe. Es una responsabilidad que va más allá de lo que hago" (Lévinas, 1991, p. 90). En consecuencia, lo más humano del ser humano es desvivirse con y por el otro ser humano.

El pensamiento levinasiano le da un vuelco a la manera en que comprendemos la subjetividad y la responsabilidad. La metafísica tradicional encerró la responsabilidad en el ámbito de los iguales, de la justicia, del derecho, mientras que la perspectiva levinasiana la entiende dentro de una necesaria asimetría en la cual "el 'no matarás' es la primera palabra del rostro" (Lévinas, 1991, p. 83). El rostro del otro, si lo observo existencialmente, grita con voz de trueno "no me mates". Y si hay una respuesta positiva por parte de quien lo escucha, entonces, la vida sigue. Cuando el otro aparece ante mí diciendo "no me mates" no tengo ante mí otro ser que lucha por seguir siendo, sino un ser debilitado que en su flaqueza concentra toda la fuerza moral de la diferencia y que desde su anterioridad hace que la visión de su rostro me atrape en la responsabilidad por su suerte (López, 2004, p. 100).

Echavarría (2009, p. 221) dice que al contemplar a otras personas como víctimas se ve algo verdadero sobre ellas y sobre la vida. Estas condiciones de debilidad, necesidad o carencia brindan a las personas de buena voluntad fuertes motivos para hacer algo. Si bien la víctima nos alerta de que hay algo que no está bien, que padece una condición de inequidad social que no se ha causado ella misma y la contemplamos en el sentido de que vemos su soledad, su pobreza, su enfermedad o su frustración, también nos vemos impulsados por la obra a observarla como un ser capaz de distintas formas de actividad.

Sumado a lo anterior, esta acción en favor del otro tiene un retorno,

La víctima muestra algo sobre nuestras propias vidas; ilustra la vulnerabilidad y la desgracia que todos podríamos padecer; que no somos tan diferentes de las personas cuyo destino observamos y que tenemos, en consecuencia, razones para temer reveses parecidos (Echavarría, 2009, p. 221).

El rostro del otro que clama "no me mates" también me recuerda que yo puedo morir. Tan sagrada como la vida del otro es mi propia vida; si la profano, también la mía podría ser profanada.

Por su parte, Panikkar (2006, p. 76) señala que a causa del mythos del individualismo occidental moderno, muchos idiomas europeos 
no distinguen entre dos palabras latinas aliusa-ud y alter-a-um (ali-terus), traducidas ambas como otro. Sin embargo, la primera se traduce como 'extraño' o 'extranjero' y la segunda como 'prójimo'. Si el otro, hombre o mujer, es un extranjero (alius), hemos de resignarnos a la imposibilidad de conocer al otro como otro. Si el otro es mi prójimo (alter), entonces "yo puedo conocer al otro como a la otra parte de mí mismo y complemento de mi autoconocimiento". Si el otro es concebido como alius, un extraño, se convierte en el homo homini lupus proclamado por Hobbes en El Leviatán. La distancia entre los seres humanos se hace abismal y prima la desconfianza. El otro como alius demanda seguridad sobre la base de la fuerza (política, física, económica, militar, religiosa, etc.); en cambio, si el otro es un alter, emerge la confianza en lo humano.

Entonces, ¿qué pueden hacer las religiones para que cada ser humano - no solo sus miembros- se apropie en su corazón del mandato "toda vida es sagrada, ergo, debo respetarla hasta las últimas consecuencias?

\section{El cuidado de "los otros"}

La ontonomía ${ }^{7}$ nos hace conscientes de que solo podemos ser si salvamos la armonía en cada una de nuestras relaciones porque, simplemente, somos interdependientes. El ser humano se constituye con sus semejantes, con los cuales tiene una mutua pertenencia y vive en continua dependencia. El hombre no está solo, ni puede sobrevivir ni desarrollarse así, sino siempre con el otro. Ser persona significa ser con y para los demás. Este principio está en la base de la solidaridad: ontológicamente pertenecemos al otro, a los demás, y ellos nos pertenecen; constituimos con ellos in solidum una misma realidad solidaria. Pero no solo ontológicamente, sino también afectiva y socialmente.

De la misma manera, este principio nos permite comprender nuestra naturaleza política. No

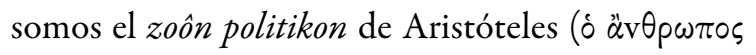

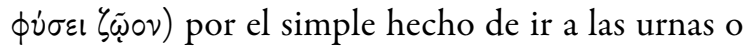
pertenecer a un partido político; somos seres políticos si aspiramos al bien común de la polis. "La política es verdaderamente el arte de vivir la plenitud del ser humano" (Panikkar, 1999, p. 63). Recordemos que la polis, de acuerdo con su sentido griego, es ese pequeño mundo en el que la persona alcanza su realización (Panikkar, 1983, p. 45).

La política va más allá de un quehacer funcionalista que busca metas cortoplacistas. Esta tiene una meta clara: la convivialidad, la vida feliz, la plenitud del ser humano. Insistimos, la polis es el lugar de encuentro de hombres y mujeres que buscan el bien común por medio de su ejercicio político. El bien común se alcanza mediante la praxis y esta lleva a "la buena vida" ( $\varepsilon \tilde{u} \zeta \nu \tilde{\eta})$ (Panikkar, 1999, p. 76). Por consiguiente, es posible intuir que una forma de praxis, tal vez la más conveniente para la gran polis colombiana, es el cuidado de los otros. Esta aparece como una responsabilidad para el tiempo presente.

Hablar de responsabilidad también trae como consecuencia hablar de ciudadanía y del papel activo que debemos tener como agentes sociales autónomos, solidarios y garantes de los derechos humanos y los principios democráticos. La dignidad de cualquier persona clama por el reconocimiento de sus derechos y por la satisfacción de sus necesidades hasta donde nos sea posible. En consecuencia, el cuidado de los otros acentúa un compromiso con esos otros, especialmente con los más débiles y excluidos, para transformar los escenarios sociales en los que se producen la marginación injusta de personas y la exclusión de comunidades enteras.

Dicho de otra manera, sabemos que "ciudadana es aquella persona a la que en su comunidad política se le reconocen y protegen no solo los derechos civiles y políticos, sino también los económicos, sociales y culturales" (Cortina, 2001, p. 56). De este modo, los "bienes de la justicia"

7 Un mayor despliegue del concepto ontonomía y su relación con la naturaleza polííca del ser humano se puede ver en Meza (2010). 
aquellos que ahora identificamos como (el mínimo de la) calidad de vida, son bienes que todo ciudadano, por el simple hecho de serlo, puede exigir en la propia comunidad "por derecho"; no se trata de valores o regalos, sino de exigencias de justicia. Procurarlos en un país como el nuestro ya sería bastante.

Sin embargo, existe otra esfera de la existencia humana, no tanto vinculada a los derechos y la justicia como a la compasión y a la responsabilidad: ahí residen los "bienes de la gratuidad". Hay una gran cantidad de bienes sin los que la vida no puede ser buena y que tienen la peculiaridad de que ningún ser humano tiene derecho a ellos; ninguna persona puede reclamarlos en estricta justicia. La cita de Cortina resulta lúcida para comprender esto:

Ninguno tiene derecho a ser consolado cuando llega la tristeza...; nadie puede exigir esperanza, si ya no espera nada..., tampoco puede reivindicar que alguien le contagie de ilusión... y ni siquiera puede reclamar en una ventanilla un sentido para su vida; nadie tiene derecho a ser amado cuando le hiere la soledad..., ni tiene derecho a confiar en que el final de la historia no sea el más rotundo de los fracasos o la más insustancial banalidad. No son estos bienes a los que "se tiene derecho" y que otros tienen "el deber" de proporcionar; sin embargo, son necesidades que las personas tenemos para llevar adelante una vida buena, son necesidades que solo se pueden acallar con los otros. Con otros que han descubierto no el deber de la justicia, sino la ob-ligación graciosa de tener los ojos bien abiertos ante el sufrimiento [...] Todo reside en el descubrimiento de ese vínculo misterioso que lleva a compartir lo que no puede exigirse como un derecho ni darse como un deber, porque entra en el ancho camino de la gratuidad. (Cortina, 2001, pp. 168-171).

Entonces, ¿qué acciones podrían realizarse interreligiosamente para procurar, de un lado, los derechos humanos, la justicia y la responsabilidad, y de otro, la gratuidad y la misericordia?

\section{El cuidado de "lo otro", de nuestra casa común}

En los tiempos actuales tenemos una sensibilidad ecológica a flor de piel que nos exige extender el cuidado al mundo en el cual vivimos. Una determinada perspectiva nos ha convencido de que la ecología es una ciencia que trata de la explotación racional de los recursos pero, a fin de cuentas, la explotación sigue ocurriendo dentro de unos límites de racionalidad bastante difusos y nuestro planeta continua gritando "no me mates" cuando nos presenta el rostro de los ríos contaminados, los bosques talados, el aire cada vez más irrespirable, el clima enloquecido, el supercalentamiento del planeta y la extinción total de muchas especies. En la encíclica Laudato si', de reciente aparición, el papa Francisco habla de esta manera en referencia al cuidado de la casa común:

Esta hermana clama por el daño que le provocamos a causa del uso irresponsable y del abuso de los bienes que Dios ha puesto en ella... La violencia que hay en el corazón humano, herido por el pecado, también se manifiesta en los síntomas de enfermedad que advertimos en el suelo, en el agua, en el aire y en los seres vivientes. Por eso, entre los pobres más abandonados y maltratados, está nuestra oprimida y devastada tierra, que "gime y sufre dolores de parto" (Rm 8, 22). (Francisco, 2015, n. 2)

El cuidado por la naturaleza descentra el discurso y su praxis para que sean menos antropocéntricos y más biocéntricos. De hecho, una ética antropocéntrica justificó una libertad sin límites y una ausencia de responsabilidad frente a conductas de absoluto desprecio por la vida en sus múltiples manifestaciones. Hoy, más que nunca, es necesario cultivar una actitud ecosófica que trae consigo, entre otras cosas, una sabiduría en la relación ser humano-naturaleza (Meza, 2010).

Por lo tanto, vale la pena preguntarse: ¿qué responsabilidades hemos de asumir los seres 
humanos (los creyentes) en relación con toda forma viviente? La pregunta no es banal porque, si hemos comprendido el principio de interdependencia señalado arriba, de su respuesta depende nuestra supervivencia - la mía, la tuya, la de los otros y la del mundo-. El ser humano solo puede mantenerse a expensas de los otros y de la naturaleza porque somos una realidad cosmoteándrica (Meza, 2009).

No hay opción: tenemos que asumir nuestra responsabilidad para con el mundo. Hans Jonas afirma que quien se siente efectivamente responsable es aquel a quien le es confiada la guarda de algo perecedero. ¿Y qué hay más perecedero que observar a la vida marcharse hacia la muerte por la inconsecuente intervención del hombre? Son emblemáticos los peligros que afectan el ecosistema, dentro del cual se desarrollan las actividades humanas, o los que resultan de la manipulación biológica aplicada a la reproducción humana, o a la identidad genética de la especie humana, o a la intervención química o quirúrgica sobre el comportamiento del hombre. En suma, debido a la técnica, el hombre se volvió peligroso para el hombre, en la medida en que pone en peligro los grandes equilibrios cósmicos y biológicos que constituyen los cimientos vitales de la humanidad (De Siqueira, 2001, p. 283).

En el momento actual hay una representación de un futuro que tal vez no se realice, pero que expone su testimonio en el presente como caracterización de una desdicha, como imagen de lo no querido y, sobre todo, presentando enfáticamente la necesidad de instituir un nuevo estatuto de responsabilidad de los hombres que tenga por objetivo el sustento de la vida ${ }^{8}$. Jonas sostiene la po- sibilidad escatológica de que la muerte sustituirá a la vida, a menos que la "heurística del temor" (Jonas, 2001, p. 74) nos mueva a encontrar otros caminos de acción que conlleven la salvaguarda de la vida que, por supuesto, incluyan la nuestra. Esto ha de ser una empresa de toda persona religiosa, como bien lo dice el papa Francisco:

La mayor parte de los habitantes del planeta se declaran creyentes, y esto debería provocar a las religiones a entrar en un diálogo entre ellas orientado al cuidado de la naturaleza, a la defensa de los pobres, a la construcción de redes de respeto y de fraternidad (Francisco, 2015, p. 201).

\section{A manera de conclusión}

El anhelo de paz de nuestro país resulta propicio para el encuentro de creencias y religiones tanto en clave de ecumenismo como de diálogo interreligioso. Hoy por hoy se están dando algunos signos de los tiempos que pueden hacer realidad una unidad en la diversidad religiosa.

Tal vez, para concluir, sea necesario decir que toda acción exterior debe ser reflejo de lo que vivimos en nuestro interior. Para nuestro caso, todo lo que hagamos por la paz debe estar sostenido por una profunda experiencia personal de fe cuyo pilar sea justamente la paz, de modo tal que podamos comunicarla a los otros. Reconocer los asomos de beligerancia, violencia o altanería en la vida cotidiana es un primer paso, pero no basta; es necesario cultivar en nosotros la paz interior, esa que nos permite ver más allá de nosotros mismos, escuchar con profundidad, dialogar con sinceridad, aceptar al otro como una parte de nosotros y construir conjuntamente.

8 De Siqueira aclara que hasta hace poco la naturaleza no era objeto de responsabilidad humana, pues cuidaba de sí misma. Pero, como la ética tiene que ver con el aquí y ahora, es necesario un cambio de los antiguos imperativos éticos, entre los cuales el imperativo kantiano constituye el parámetro ejemplar "actúa de tal modo que el principio de tu acción se transforme en una ley universal". Jonas propone un nuevo imperativo: "actúa de tal modo que los efectos de tu acción sean compatibles con la permanencia de una vida humana auténtica", o de modo negativo "no pongas en peligro la continuidad indefinida de la humanidad en la Tierra" (2001, p. 279). 


\section{Referencias}

Alonso, A. (2008). Exclusión y diálogo en la confrontación de hegemonías. Notas sobre la relocalización de influencias en el campo religioso latinoamericano. En Alonso, A. (Comp.). América Latina y el Caribe. Territorios religiosos y desafíos para el diálogo. Buenos Aires: Consejo Latinoamericano de Ciencias Sociales.

Amaladoss, M. (1988). Diálogo y misión. ¿Realidades en pugna o convergentes? Selecciones de Teología, 108, 243-258.

Beltrán, W. (2006). De microempresas religiosas a multinacionales de la fe. La diversificación del cristianismo en Bogotá. Bogotá: Universidad San Buenaventura.

Bidegaín, A. \& Demera, J. (2005). Globalización $y$ diversidad religiosa en Colombia. Bogotá: Universidad Nacional de Colombia.

Cortina, A. (2001). Alianza y contrato. Madrid: Trotta.

De Siqueira, J. (2001). El principio de responsabilidad de Hans Jonas. Acta bioethica. 7 (2), 277-285.

Dupuis, J. (2000). Hacia una teología cristiana del pluralismo religioso. Santander: Sal Terrae.

Echavarría, Carlos (2009). La formación avanzada en clave ético-moral y política ¿Por qué y para qué la formación política y para la ciudadanía en Colombia? Actualidades Pedagógicas, $54,213-225$.

Forcano, B. (2008). El diálogo interreligioso camino para la paz. Recuperado el 25 de septiembre de 2015, de http://www.alainet.org/ en/node/130423.

Francisco. (2015). Carta encíclica Laudato si' sobre el cuidado de la casa común. Vaticano: Editorial Vaticana.
Houtart, F. (2001). Mercado y religión. San José de Costa Rica: Departamento Ecuménico de Investigaciones.

Jonas, H. (2001). Más cerca del perverso fin. Madrid: Catarata.

Küng, H. (1999). Una ética mundial para la economía y la politica. Madrid: Trotta.

Lévinas, E. (1991). Ética e infinito. Madrid: Visor.

Ligorio, A. (2001). Algunos desafíos del diálogo interreligioso en América Latina. Iglesia Viva, 208, 19-29.

López, E. (2004). De la autonomía a la pasividad: reflexiones en torno al sujeto moral. Bogotá: Pontificia Universidad Javeriana.

Meza, J. (2010). Homo politicus: una lectura teológica de la dimensión política del ser humano desde el pensamiento de R. Panikkar. Actualidades pedagógicas, 55 (enero-junio), 71-85.

Meza, J. (2009). El ser humano como realidad cosmoteándrica. Cuestiones teológicas, 85, 59-80.

Meza, J. (2010). Ecosofía: Otra manera de comprender y vivir la relación hombre-mundo. Cuestiones teológicas, 87 (enero-junio), 119-144.

Pablo VI (1965). Declaración sobre las relaciones de la Iglesia con las religiones no cristianas - Nostra Aetate. Recuperado de http://www.vatican.va/archive/hist_ councils/ii_vatican_council/documents/ vat-ii_decl_19651028_nostra-aetate_sp.html.

Panikkar, R. (1983). Religion or politics. The Western Dilemma. En Merkl, P. \& Smart, N. (Eds.). Religion and Politics in the modern world (pp. 44-60). Nueva York: NY University Press. 
Panikkar, R. (1999a). El espiritu de la politica. Homo politicus. Barcelona: Península.

Panikkar, R. (1999b). La nueva inocencia. Pamplona: EVD.

Panikkar, R. (2005). Diálogo inter e intrarreligioso. En Tamayo, J. Nuevo diccionario de teologia (pp. 425-433). Madrid: Trotta.

Panikkar, R. (2006). Paz e interculturalidad. Una reflexión filosófica. Barcelona: Herder.

Panikkar, R. (2007). Mito, fe y hermenéutica. Barcelona: Herder.
Pérez, V. (2014). La búsqueda de la armonía en la diversidad. El diálogo ecuménico e interreligioso desde el Concilio Vaticano II. Estella: Verbo Divino.

Ramírez, J. (2008). El campo religioso latinoamericano y caribeño. Efectos de la globalización neoliberal. En Alonso, A. (Comp.). América Latina y el Caribe. Territorios religiosos y desafios para el diálogo. Buenos Aires: Consejo Latinoamericano de Ciencias Sociales.

Vila, E. (2004). Pedagogía de la ética: De la responsabilidad a la alteridad. Athenea Digital, 6, 47-55. 